\title{
La eficacia de una dieta para bajar de peso no depende de su composición en macronutrientes
}

\author{
Diet efficacy to loose weight does not depend on it's macronutrients composition
}

Sacks F y col. N Engl J Med 2009;360:859-73.

\author{
Objetivo \\ Comparar el efecto sobre el peso corporal de cuatro dietas \\ hipocalóricas con diferente composición de macronutrientes.
}

\section{Diseño, lugar y pacientes}

Ensayo clínico aleatorizado doble ciego con dos años de seguimiento realizado en dos centros: Harvard School of Public Health and Brigham and Women's Hospital, Boston; y Pennington Biomedical Research Center del University System del Estado de Louisiana, Baton Rouge. Fueron incluidos 811 individuos de 30 a 70 años con un Indice de Masa Corporal de 25 a 40 . Fueron excluidos los individuos con diabetes o con enfermedad cardiovascular inestable; quienes estuvieran recibiendo medicación que afectara el peso corporal y quienes no tuvieran la motivación adecuada.

\section{Intervención y medición de resultados principales}

Se los aleatorizó a la prescripción de una de cuatro dietas diferentes en cuanto a su composición de grasas, proteínas e hidratos de carbono, respectivamente: 1) 20,15 y $65 \%$; 2) 20 , 25 y $55 \%$; 3) 40,15 y $45 \%$, 4) 40,25 y $35 \%$.

Todas las dietas estuvieron conformadas por alimentos similares y los participantes recibieron instrucciones en sesiones individuales y grupales durante los dos años que duró el estudio. El resultado principal se definió como el cambio en el peso corporal a los dos años de la intervención. Se realizó un análisis por intención de tratar, considerando dos comparaciones factoriales*: a) dieta baja en grasas vs. dieta elevada en grasas; b) dieta con aporte promedio de proteínas vs. dieta alta en proteínas. También se efectuó una comparación entre las dietas con alto y bajo contenido de hidratos de carbono.

\section{Resultados principales}

El descenso de peso ocurrió principalmente durante los primeros seis meses del tratamiento, con una pérdida promedio de $6 \mathrm{~kg}$ que representó el $7 \%$ del peso inicial; comenzando lentamente luego de los 12 meses todos los grupos a ganar peso. Los individuos que asistieron a mayor cantidad de sesiones de control perdieron más peso y se observó la reducción de los factores de riesgo cardiovascular a los seis meses y a los dos años con todas las dietas. A los dos años, la pérdida de peso fue similar en los participantes asignados a una dieta con $25 \%$ de proteínas y aquellos que siguieron una dieta con $15 \%$ de proteínas ( 3,6 y $3 \mathrm{~kg} ; \mathrm{p}=0,22$ ); en aquellos asignados a una dieta con $40 \%$ de grasas y aquellos que siguieron un plan con un $20 \%$ (3,3kg en ambos grupos; $p=0,94)$; $y$ en el grupo que siguió una dieta con $65 \%$ de hidratos de carbono y el que siguió un plan con $35 \%(2,9$ y $3,4 \mathrm{~kg} ; \mathrm{p}=0,42)$.

\section{Conclusiones}

El tratamiento con diferentes dietas hipocalóricas produjo un descenso de peso significativo sin importar la composición en macronutrientes de las mismas.

Palabras claves: dieta hipocalórica, dieta hiperproteica, dieta hipograsa, dieta hipergrasa, sobrepeso, obesidad, tratamiento.

Keywords: hypocaloric diet, hyperproteic diet, hypolipidic diet, hyperlipidic diet, overweight, obesity, treatment.

Fuentes de financiamiento: National Heart, Lung, and Blood Institute; General Clinical Research Center, National Institutes of Health.

\section{Comentario}

La obesidad se ha convertido en el problema nutricional de mayor prevalencia a nivel mundial, pero aún continúa el debate sobre cuál es plan de alimentación que resulta más efectivo para su tratamiento.

En la actualidad, las Asociaciones Norteamericanas del Corazón y de Diabetes recomiendan para el tratamiento de la obesidad consumir un plan de alimentación que aporte menos de $30 \%$ de grasas. Por otra parte, han surgido estudios que documentaron que la pérdida de peso fue más efectiva con dietas altas en grasas y bajas en hidratos de carbono. Sin embargo, los beneficios a corto plazo de estas últimas no se mantienen a largo plazo y luego de 12 meses, la pérdida de peso no difiere en forma significativa de la obtenida con las dietas bajas en grasas y altas en hidratos de carbono'.

En el trabajo que hemos resumido, Sacks vuelve a documentar que los individuos que lograron un mayor descenso de peso fueron aquellos que asistieron a mayor cantidad de sesiones de control, lo que coincide con otros trabajos en los que se señala a la adherencia al tratamiento como un factor clave para obtener resultados exitosos a largo plazo².

La evidencia actual indica que el tratamiento adecuado para la obesidad es el que se adapta a las necesidades de cada persona contemplando la adecuación calórica, el cambio de hábitos y conductas y la realización de actividad física, sin olvidar la implementación de estrategias orientadas a mantener la motivación del individuo en el tiempo.

\section{Conclusiones de la comentadora}

Más allá del tipo de dieta prescripta, el mejor predictor de éxito es el esfuerzo del paciente; resultando ineficientes en el largo plazo todos los planes de alimentación. Para lograr una pérdida de peso que se mantenga en el largo plazo, recomendamos brindar un plan de tratamiento focalizado en cambios del estilo de vida, que se adapte a las necesidades y preferencias de cada individuo.

Alejandra Delfante [ Servicio de Alimentación del Hospital Italiano de Buenos Aires. ] alejandra.delfante@ @ospitalitaliano.org.ar

Delfante A. La eficacia de una dieta para bajar de peso no depende de su composición en macronutrientes. Evid. Act. Pract. Ambul. 12(3). 92. Jul-Sep. 2009. Comentado de: Sacks F y col. Comparison of Weight -Loss Diets with Different Compositions of Fat, Protein and Carbohydrates. N Engl J Med 2009; 360: 859-73. PMID: 19246357. Disponible en URL: http://content.nejm.org/cgi/content/abstract/360/9/859

Referencia

1. Mc Laughlin T y col. Effects of moderate variations in macronutrient composition on weight loss and reduction in cardiovascular disease risk in obese, insulin - resistant adults Am J Clin Nutr 2006; 84: 13-21.

2. Dansinger M y col. Comparison of the Atkins, Ornish, Weight Watchers, and Zone diets for weight loss and heart disease risk reduction: a randomized trial. JAMA 2005; 293: 43:53. 